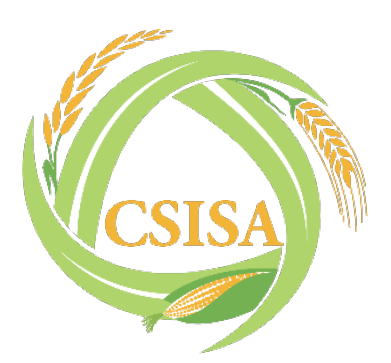

The Cereal Systems Initiative for South Asia (CSISA) is a regional initiative to sustainably increase the productivity of cereal-based cropping systems, thus improving food security and farmers' livelihoods in Bangladesh, India and Nepal. CSISA works with public and private partners to support the widespread adoption of resource-conserving and climate-resilient farming technologies and practices. The initiative is led by the International Maize and Wheat Improvement Center (CIMMYT), implemented jointly with the International Food Policy Research Institute (IFPRI) and the International Rice Research Institute (IRRI), and is funded by the US Agency for International Development (USAID) and the Bill \& Melinda Gates Foundation.

\section{Regressing Forward: Agriculture Mechanization subsidy modalities in Bihar and Odisha}

Smriti Saini, Avinash Kishore, Muzna Fatima Alvi | February 2020

\section{Introduction}

Farm mechanization is indispensable for enhancing agricultural productivity across the country. Over the years, the Indian government has instituted several schemes and programs to promote agricultural mechanization in the country. Until recently, state and central government schemes took the form of price subsidies, especially targeting critical farm equipment. More recently, the government has shifted to direct benefit transfers (DBT) for all agricultural inputs, including farm implements. While the central government instituted the broader schemes and programs, the specifics concerning subsidy disbursement have been left to state governments, with flexibility on which implements to promote and how much and when to disburse subsidy payments. These broad guidelines have been enshrined in several programs, chief among which is the National Mission on Agriculture Extension and Technology (NMAET).

\section{Farm Power Availability in Eastern India}

As of 2013-14, average national farm power availability is $2.02 \mathrm{~kW} /$ hectare (Farm Mechanisation, 2017); however, there is considerable heterogeneity across states, with some states such as Bihar and Odisha reporting farm power availability less than one $\mathrm{kW} /$ hectare. In general, the eastern parts of the country have significantly lower farm power availability than the national average. Despite this, a large share of their population continues to rely on agriculture as the primary source of income. More than sixty percent of the population in Odisha and Bihar depend on agriculture and the states have not yet realized their mechanization potential, an input crucial for the agriculture sector (Agriculture Department, Odisha, 2015) (Census of India, 2011). Low rates of mechanization also affect labor productivity, as demonstrated by the low labor productivity of paddy in the states (Figure 1).

Both central and state schemes support farm mechanization initiatives in India, the leading ones being SMAM and RKVY (and its revised iteration RKVY-RAFTAAR). The SMAM is perhaps the largest mechanization focused scheme in India with a total budgetary outlay of 11.6 billion rupees (USD 163.5 million) for the year 2018-191.The states of Odisha and Bihar have been subsidizing the sale of agriculture equipment under SMAM, State Plans, and other agriculture schemes. Apart from the individual farmer subsidies, financial assistance is also offered on packages of machinery to enable the setting up of custom hiring centers $(\mathrm{CHC})$ for the benefit of small farmers. The limited success of $\mathrm{CHC}$, coupled with high rental rates for machinery in the region, has precluded small farmers from benefiting from these enterprises. Overall, despite myriad policy interventions, a large proportion of the population remains devoid of the benefits of mechanization. 
Figure 1: Labor Productivity of paddy (Rs/hour) 2015-2016

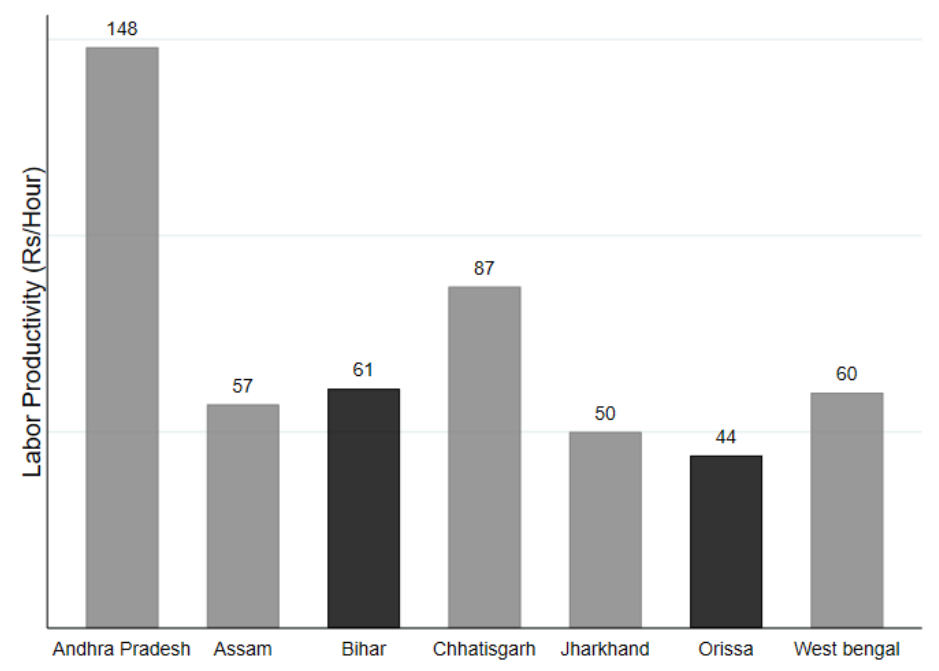

Source: Commission for Agriculture Cost and Prices

In the 2018-19 budget, Odisha allocated $6.9 \%$ of its total budget to agriculture and allied activities. Bihar's allocation stood at $1.6 \%$ which was significantly lower than the national average of $6.4 \%$ (PRS India, 2018). While there has been a steady increase in the state expenditures on farm mechanization in Odisha, Bihar has only seen a rise in spending since 2017 after decreasing expenditures in the past few years (Figure 2).

Figure 2: Budget expenditure on popularization of agriculture mechanization initiatives (Rs Lakhs)

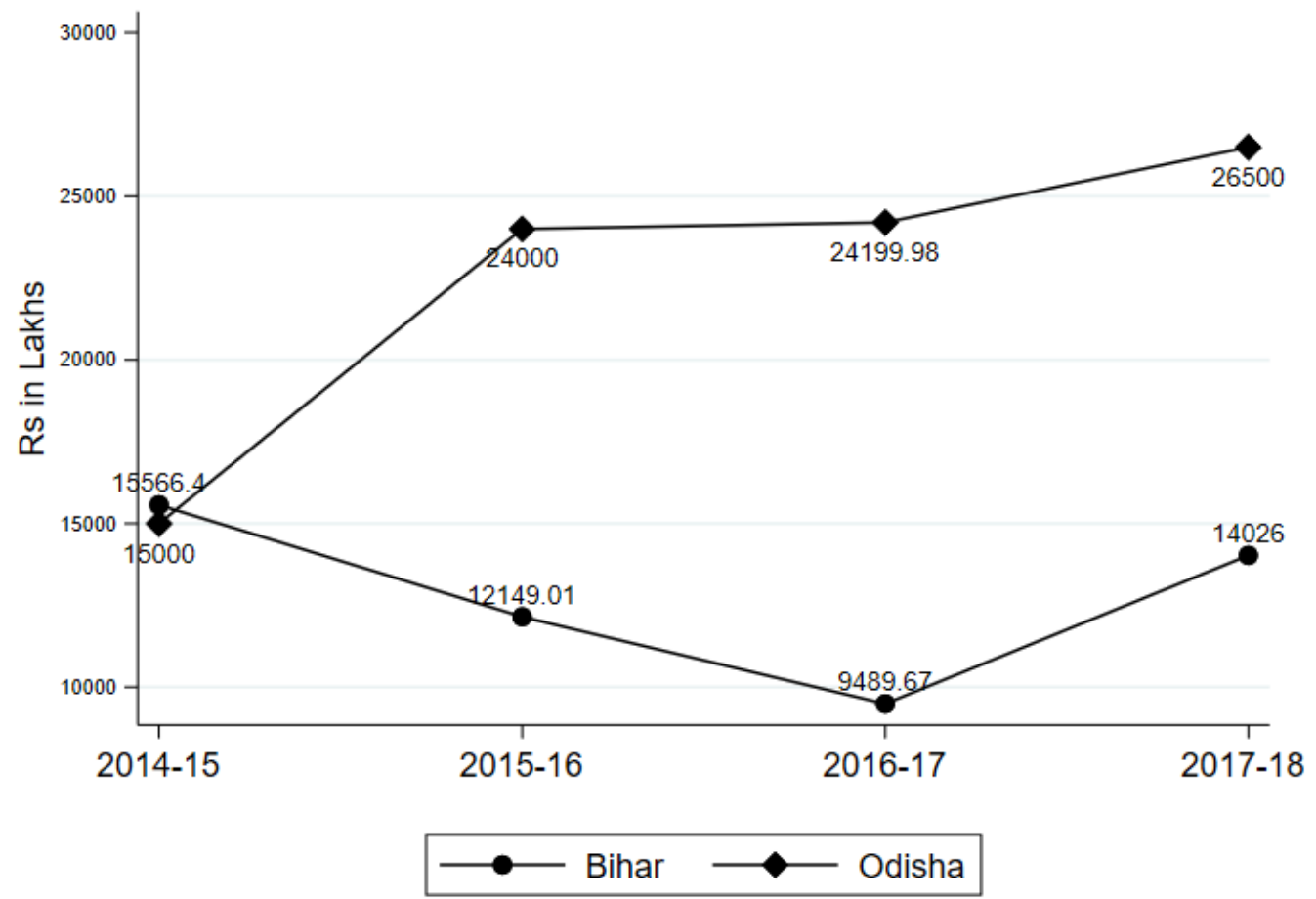

Source: Bihar Budget (2016-2019), Odisha budget (2016-2019) 


\section{Data and Methods}

A review of the existing policies and beneficiary data on farm mechanization forms the background for the paper. For our analysis, we used individual-level subsidy beneficiary data that is available on the farm mechanization portal ${ }^{1}$ of the respective states. The datasets have beneficiary-level information on implement subsidy availed and other associated details. The OFMAS data for Bihar beneficiaries contains nearly 0.44 million individual transactions of subsidized agricultural equipment given to farmers. We also analyzed the AGRISNET dataset of over forty-five thousand mechanization transactions in Odisha. While the years of data availability differ across the two states, thus precluding strict comparability, the large number of data points allow us to do rich descriptive analysis.

We also conducted unstructured detailed interviews with stakeholders in both the states, to trace the offline process and deviations from the formal process wherever applicable. The key informants included machine dealers, officials at the agriculture engineering department of the states, and beneficiary farmers.

\section{Results}

Both Odisha and Bihar have laid an increasing focus on delivering mechanization services to the farmers. Implements worth more than INR 20 billion (USD 280.7 million) were sold under subsidy in Bihar during 2014-2019 and more than INR 9.5 billion (USD 133.3 million) worth implements were sold in Odisha during 2014-2016. Figure 3 reflects the total mechanization subsidy as a fraction of the net sown area in the districts.

Figure 3: Rupees of machine subsidy received per ha of net sown area across districts
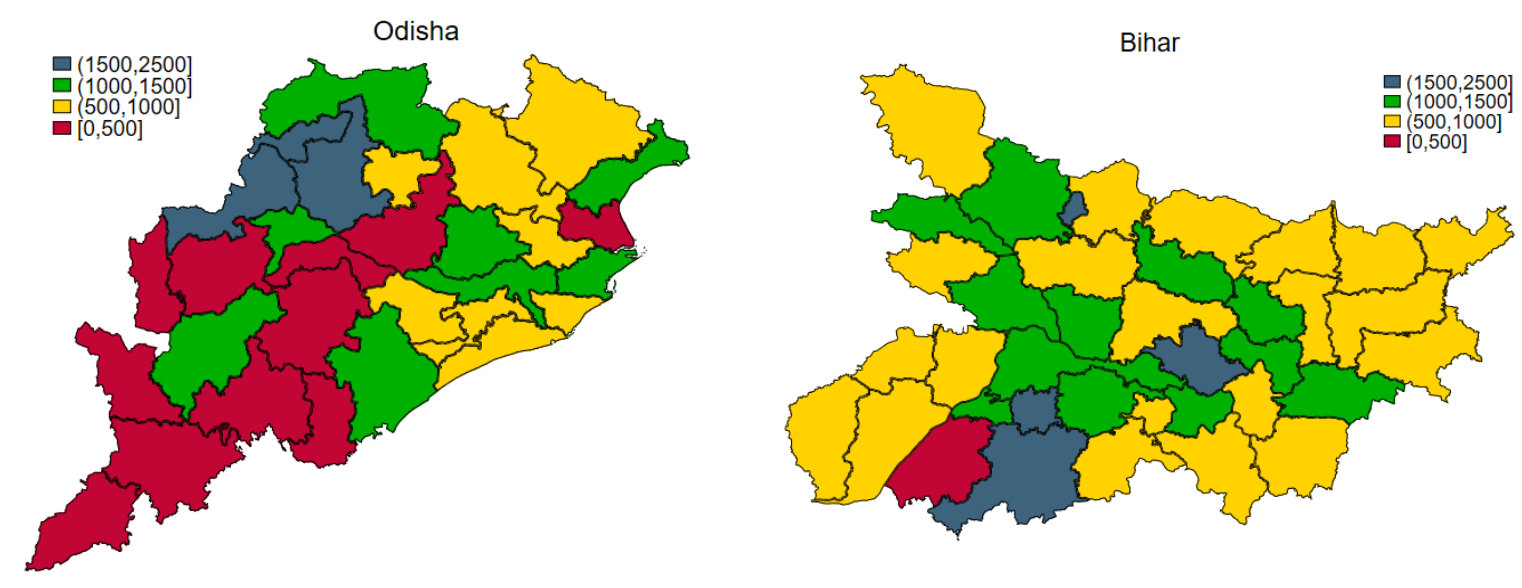

Source: Directorate of Agriculture \& Food Production, Odisha; Department of Agriculture, Bihar

During $2014-2016$, women formed $11.6 \%$ of farm mechanization beneficiaries in Odisha. The lack of gender identification variables in Bihar beneficiary data makes it difficult to deduce female beneficiaries. Among the most popular subsidized implements in Bihar were irrigation pipe, chaff cutter, rotavator, cultivator, sprayer duster, pumpset. Power tiller, combine

\footnotetext{
${ }^{1}$ The portals can be accessed at http://farmech.bih.nic.in/FMNEW/Home.aspx for Bihar and http://agrisnetodisha.ori.nic.in/FMNEW/Home.aspx for Odisha.
} 
harvester, tractor, other special power-driven equipment were among the most demanded subsidized implements in Odisha.

The SMAM guidelines followed by both states define subsidy as a proportion of the capital cost of the machine and set an upper limit on the fixed subsidy amount to be disbursed. The subsidy structure in the states favors SC/ST farmers in the form of higher subsidy rates or separate machine targets. The states also offer subsidy to promote commercial agricultureenterprises such as custom hiring centers. Odisha provides a higher subsidy rate to both women and SC/ST farmers to start CHCs. The major agents involved throughout the mechanization subsidy process are farmers, machine dealers, District Agriculture Officer, and the State Department of Agriculture. Banks, block-level coordinators and the Primary Agricultural Credit Society (PACS) also play an important role in the process. Despite extension efforts by the District Agriculture Officers (DAO), Panchayats and Krishi Vigyan Kendras, it is the dealers who serve as the first point of contact for the farmer about the product and process to avail subsidy on farm equipment.

\section{Supply bottlenecks and credit gap}

Administrative bottlenecks characterize the subsidy disbursal process in the states. An analysis of the beneficiary data of the states provides an insight into the timeline of implement supply. The supply is concentrated around the fourth quarter of the financial year in Bihar, while Odisha does not follow a similar pattern of supply (Figure 4). The process of online applications for machine subsidy in Bihar opens towards the end of the financial year and therefore, we see the bunching of subsidy disbursements around the end of the fiscal year.

Concentration around financial year results into the hasty allocations of machine targets to exhaust the budgetary allocations. This does not address the need-based demand of machines by farmers. The lack of concentration in Odisha can be attributed to the constant monitoring of implement targets. The following figures show implement delivery concentration by financial quarters in the country, where Q1 stands for the period of AprilJune, Q2 stands for the period of July-September, Q3 stands for the period of OctoberDecember, and Q4 stands for the period of January-March.

Figure 4: Concentration of Implement delivery in the states

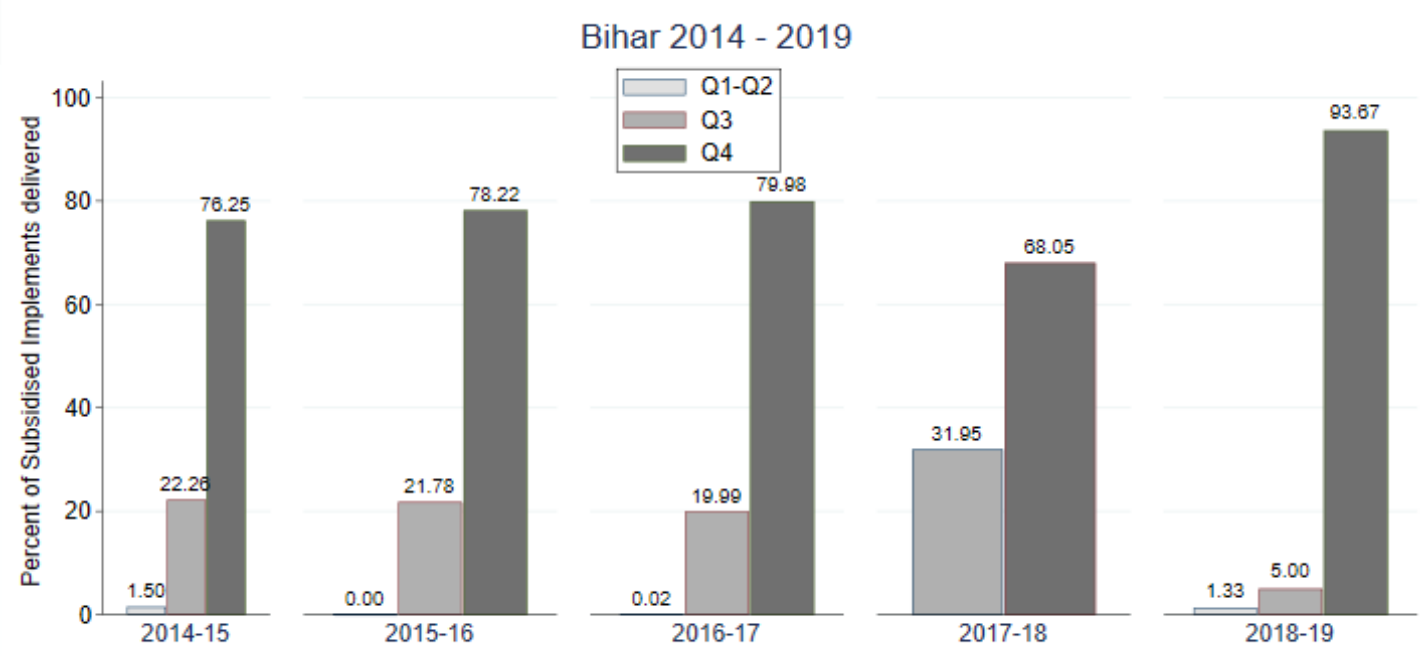




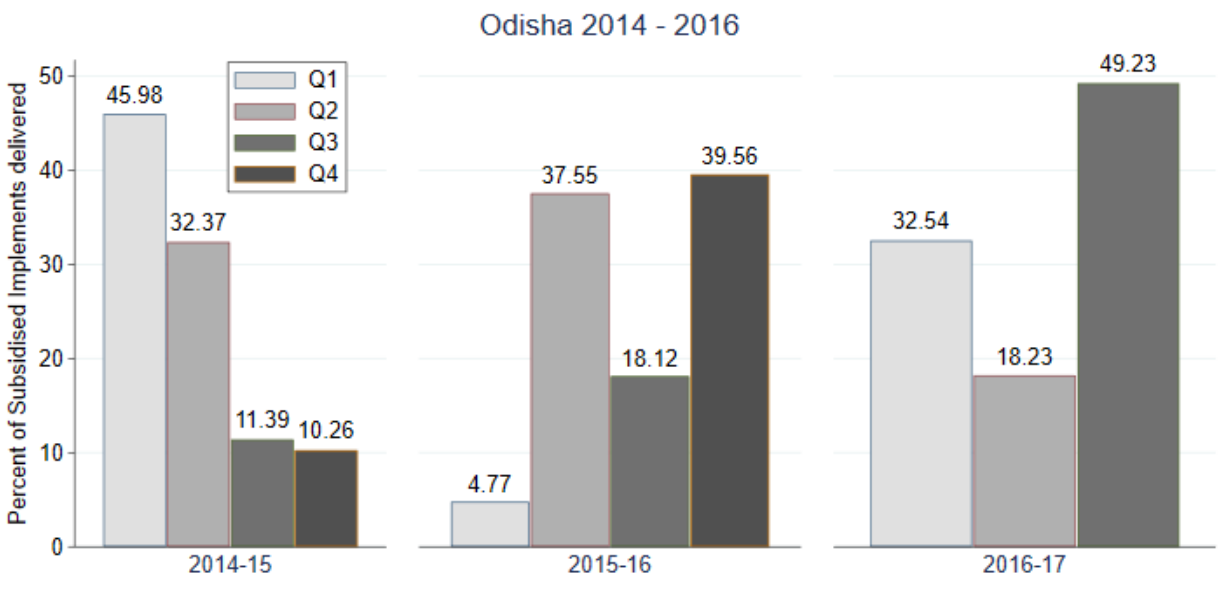

Source: Directorate of Agriculture \& Food Production, Odisha; Department of Agriculture, Bihar

As a consequence of concentration of machine delivery around March, subsidy disbursement in Bihar also centers around quarters four and one. Lack of data on timing of disbursements for Odisha prevented a similar analysis. Unlike Odisha, the entire application process is not digital in Bihar. The process of subsidy transfer to the farmers' accounts involves a tedious process which usually takes months against the scheduled target of 15 days. The delay in subsidy disbursal creates a financial burden for both the farmers and the dealers.

The current system makes it mandatory for the farmer to arrange for upfront payment of the equipment. Our interactions with the farmers and machine dealers revealed that the need to arrange for finances beforehand has created a credit gap as the farmers lack financial resources to make the upfront payments. These constraints have paved way for an informal credit structure. The dealers stand to lose out their customer base without any credit support. Consequently, they have informally switched to the pre-DBT system by accepting delayed payments from the farmers. The usual practice is to accept post-dated cheques (dated according to the subsidy disbursal) from the farmer for a proportion of the machinery price. Through our discussions with the dealers in both states, we found that this is prevalent in Bihar whereas we found lesser evidence of the same in Odisha.

\section{Time delay in subsidy disbursal}

The average number of days taken for the subsidy to reach the accounts of farmers ranges from one month to two months (Figure 5) in Bihar as against the defined timeline of fifteen days. This can be attributed to the excessive administrative layers around the process and the resulting delay in disbursal. Offline mode of subsidy transfer takes longer than stipulated time. Lack of data on the variable of interest prevented a similar analysis for Odisha. 
Figure 5: Average number of days taken to disburse subsidy in Bihar

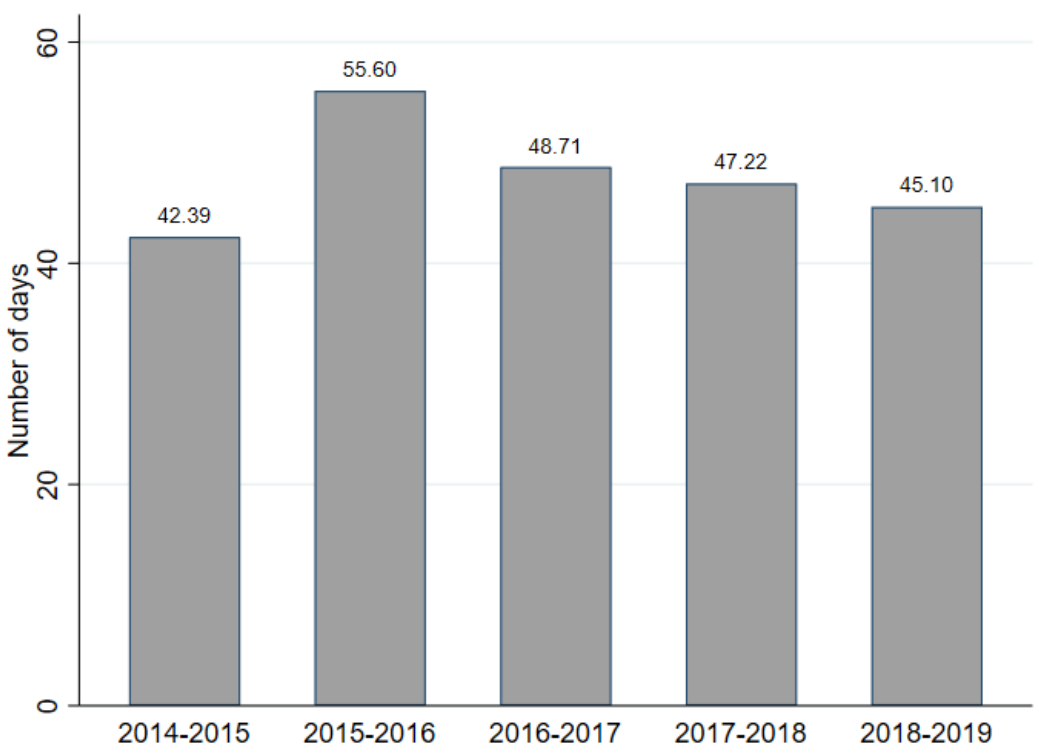

Source: Directorate of Agriculture \& Food Production, Odisha; Department of Agriculture, Bihar

\section{Targeting mechanism}

The process of mechanization subsidy starts with the defined targets for machines against which the states measure their mechanization achievements. During the financial year 20162017, Bihar only achieved $10.7 \%$ of its physical machine targets (Government of Bihar , 2018). Realization of targets has improved in Odisha over the years (Figure 6). However, the demand and supply are not uniform for all agriculture machineries.

Figure 6: Implement Target v/s Supplied (Odisha)

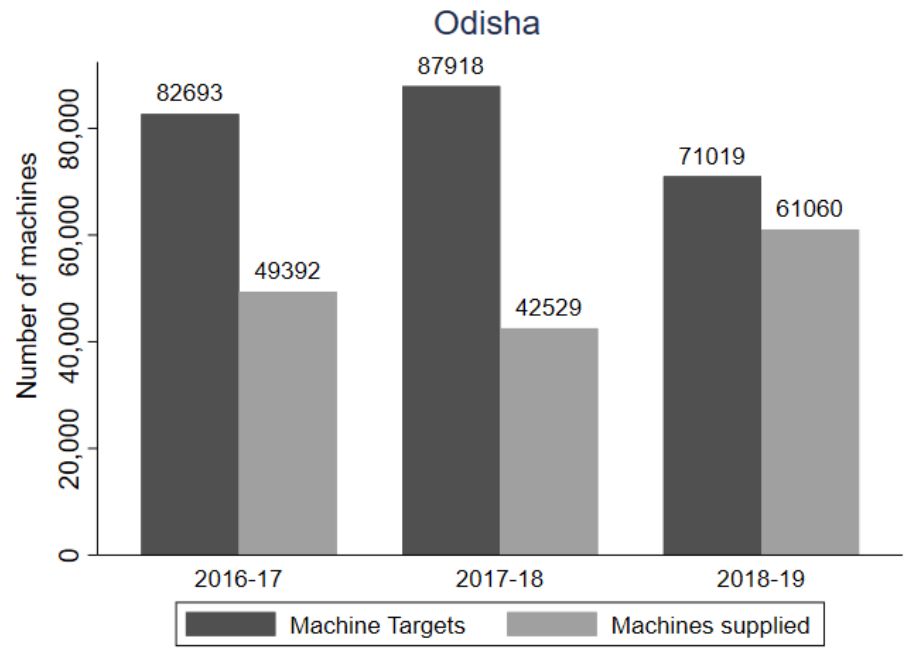

Source: Activity Report (2015-2017), Department of Agriculture \& Farmers' Empowerment, Government of Odisha, \& Directorate of Agriculture \& Food Production, Odisha 
A more efficient way would be to remove the process of target setting and allowing farmers to place their demands on the type of implements they would like to purchase. Farmers should be able to avail whichever implement they need on subsidy. In order to ensure that there is a uniform demand for all machineries, the states will have to work with agriculture extension workers to create awareness around the right machines for each step of the farming process. It also creates incentive for machine dealers to expand the market, fill in the information gap and generate new demand among farmers.

A successful example of such machine subsidy implementation is of Gujarat. There are no drip and sprinkler targets under the state's Micro-Irrigation Subsidies (MIS) which is implemented by the Gujarat Green Revolution Company Ltd. The state is deemed to be among the most successful MIS implementers. The annual achievement under the scheme was 0.106 million lakh ha/year during 2005-2014 (Sugoor).

\section{Conclusion}

Before the introduction of DBT, there were reported instances of fraud sales registered by the dealers to avail the subsidy amount. The switch aimed at reducing leakages caused by the machine vendors and preventing overutilization of subsidized resources. There is a general agreement among the involved stakeholders that the incidence of such cases has decreased post-DBT.

Potential demand among farmers can be tapped by lifting of implement targets. This will incentivize the dealers to actively promote, assist and create a bigger market for farm implements in the states. Historically, dealers have served as nodal points in expanding the reach of farm input subsidies to farmers, and hence, the success of a subsidy program also depends on dealers' role. The spread of subsidized diesel pump in Eastern UP in the 1980's could also be attributed to the strong dealer network which eased the process for farmers (Shah, 2001).

Since DBT has created credit gaps in the market, it is of paramount importance that the states try to address this issue. There is a need for a dedicated credit assistance scheme to ensure that benefits also accrue to small and marginal farmers. It calls for interest and loan payment flexibility depending on the farming seasons and, most importantly, reduced administrative hassles. Concentration around the end of financial year does not ensure seasonal and needsbased supply of machines to the farmers. There is a need to monitor the demand for implements closely, and factor that into account while deciding the process timeline. A smooth and non-disruptive transition to DBT for agriculture inputs requires that the issues faced by farmers and other stakeholders are considered.

Affordability, accessibility and streamlining of the subsidy scheme are the key issues that the states face currently. At this stage, it would require a close examination of the recent developments in the credit market, the incentive structure, and an internal assessment of the efficiency of the subsidy delivery mechanism, for the states along with other players, to fix the problem areas. 


\section{References}

Agriculture Department, Odisha. (2015). Odisha Agriculture at a Glance. Bhubaneswar:

Directorate of Agriculture and Food Production,Odisha.

Census of India. (2011). Census of India. Government of India.

Farm Mechanisation. (2017). Indian Council of Food and Agriculture.

Government of Bihar . (2018). Krishi Yantrikikaran. Department of AgricultureGovernment of Bihar.

Shah, T. (2001). Wells and Welfare in Ganga Basin: public policy and private initiative in Eastern Uttar Pradesh, India. Colombo: International Water Management Institute.

Sugoor, R. K. (n.d.).

https://macrofinance.nipfp.org.in/PDF/10_Sugoor_Micro_Irrigation_in_Gujarat.pdf. Retrieved from macrofinance.nipfp.org.in.

Government of Odisha. (2018). Activity Report.

\section{Author Details}

Smriti Saini is a Research Analyst with the International Food Policy Research Institute (IFPRI) in the South Asia Regional Office, New Delhi. Avinash Kishore is a Research Fellow with IFPRI in the South Asia Regional Office, New Delhi. Muzna Alvi is an Associate Research Fellow in the Environment and Production Technology Division, also with IFPRI and based in New Delhi. 